\title{
Diário de uma professora em crise: adaptações de aulas práticas em dias de isolamento
}

\author{
A teacher in crisis: adaptations of practical classes in isolation days
}

\section{Emanuella Scoz ${ }^{1}$ Albio Fabian Melchioretto ${ }^{2}$}

\begin{abstract}
1 Mestre em Educação pela Universidade Regional de Blumenau (2019). Especialista em Negócios da Moda pelo Instituto Brasileiro de Moda (2009).Graduada em Design de Moda pelo Centro Universitário Leonardo da Vinci (2006). Professora Substitua no IFSC Gaspar.

E-mail: manuh.scoz@gmail.com Orcid: http://orcid.org/0000-0002-1651-1345 Lattes: http://lattes.cnpq.br/3858787418552795
2 Doutorando em Desenvolvimento, pelo Programa de Pós-Graduação em Desenvolvimento Regional , Universidade Regional de Blumenau, (FURB); Mestre em educação pela Universidade Regional de Blumenau (2016), especialista em Mídias e Educação (2012); Filosofia (2010) e Gestão Escolar (2007); Graduado em Filosofia pelo Centro Universitário de Brusque (2006). Bolsista CAPES (2020-2024).
E-mail: albio.melchioretto@gmail.com Orcid: http://orcid.org/0000-0001-8631-5270 Lattes: http://lattes.cnpq.br/6198650989958494

RESUMO Este artigo tem como problema de pesquisa os desafios de comunicação entre discentes e docentes vivenciados por uma professora autointitulada em crise, durante o isolamento social em Santa Catarina, a partir de 16 de março de 2020. O objetivo deste artigo é explorar este contexto de mudanças nas práticas de ensino e comunicação, que ocorreu em turmas de ensino presencial dos cursos superiores de Design de Moda e técnicos em Modelagem do Vestuário de uma instituição de ensino federal de Santa Catarina. A partir do relato da professora, que efetuou um diário de bordo, foram encontrados dados, os quais aplicou-se método de análise cartográfica. Buscou-se conceituar a crise como um processo de mudança, e utilizou-se o conceito de phármakon em analogia às escolhas feitas durante o período. No relato foram abordadas as estratégias de comunicação vivenciadas para superação de desafios comunicacionais e os novos formatos de aula criados pela docente, utilizando as plataformas institucionais e mídias sociais já conhecidas, tais quais Whats App. O modelo de ensino que surgiu durante a pandemia foi nomeado pela equipe docente como ensino em formato remoto, um formato que não é EAD nem presencial. Foi possível concluir a existência de angústia do docente em relação ao tempo vivido, pelo excesso de informação e, ao mesmo tempo, dificuldades de comunicação entre docente e discentes.

Palavras-chave: Comunicação; Ensino Remoto; COVID-19.

ABSTRACT This article has as a research problem the communication challenges between students and teachers experienced by a self-titled teacher in crisis, during social isolation in Santa Catarina, from March 16, 2020. The objective of this article is to explore this context of changes in teaching and communication practices, which took place in face-to-face teaching classes in the Fashion Design and Techniques in Clothing Modeling courses at a federal educational institution in Santa Catarina. From the teacher's report, which made a logbook, data were found, which was applied to the cartographic analysis method. We tried to conceptualize the crisis as a process of change, and the concept of phármakon was used in analogy to the choices made during the period. The report addressed the communication strategies experienced to overcome communication challenges and the new lesson formats created by the teacher, using the institutional platforms and social media already known, such as WhatsApp. The teaching model that emerged during the pandemic was named by the teaching team as teaching in a remote format, a format that is neither distance learning nor face-to-face. It was possible to conclude the teacher's anguish in relation to the time lived, due to the excess of information and at the same time communication difficulties between 
the teacher and students.

Keywords: Communication; covid-19; remote teaching.

\section{INTRODUÇÃO}

A noite do réveillon é marcada por uma determinada celebração. Uma reunião de amigos, um jantar característico com roupas adequadas em cores específicas, votos pessoais, desejos e metas para se realizar no tempo que se desvela. Mas, nem no pior cenário imaginário, alguém poderia celebrar um contexto tão estranho e diferente para o ano de 2020. O novo é um tempo marcado por uma crise sanitária mundial, isolamento social, debates econômicos como o papel intervencionista do Estado por parte dos defensores do estado mínimo, restrições no ir e vir e tantas outras características que, passados quatro meses veríamos a conhecer. Uma mudança drástica que certamente alterará também os votos da celebração de início de ano. No contexto de mudanças, o sistema educacional, como todo o mundo, diante das mudanças reinventouse, buscando alternativas no ensinar e aprender. Percebeu-se, durante o período de isolamento, que a comunicação entre discentes e docentes, bem como entre as equipes docentes, era o primeiro e principal desafio a ser superado. Este relato pretende explorar este contexto de mudanças, dado por conta da pandemia mundial do COVID-19, a partir dos relatos vivenciados por uma professora. São abordadas as estratégias de comunicação vivenciadas para superação de desafios comunicacionais durante o isolamento social, e os novos formatos de aula criados pela docente, utilizando as plataformas institucionais e mídias sociais já conhecidas, tais quais Whats $A p p$. O modelo de ensino que surgiu durante a pandemia foi nomeado pela equipe docente como ensino em formato remoto.

O território deste relato tem núcleo central de acontecimentos, os meses de março e abril do ano de 2020, vivenciados a partir dos decretos de isolamento social, consequentes da Pandemia do COVID-19. Chamaremos de COVID-19, que é nome oficial da doença, adotado pela Organização Mundial da Saúde (OMS). Não temos por objetivo discutir elementos técnicos do surgimento do vírus, como também, as medidas políticas-sanitárias tomadas. Dadas estas condições, o objetivo será cartografar a experiência vivencial de uma professora em regime de isolamento social. A pandemia do COVID-19, teve os primeiros casos conhecidos e registrados no final de 2019, na província de Hubei, China. Espalhou-se rapidamente transformando-se numa crise sanitária global. Segundo Mattei (2020), diante da inexistência de um medicamento seguro para o controle da transmissão e dos doentes a OMS orientou o distanciamento e o isolamento social, a constante higienização de mãos e o uso de máscaras como medidas protetivas. 
Gráfico 1: Número de contaminados pelo Coronavírus/ Number of people infected with Coronavirus

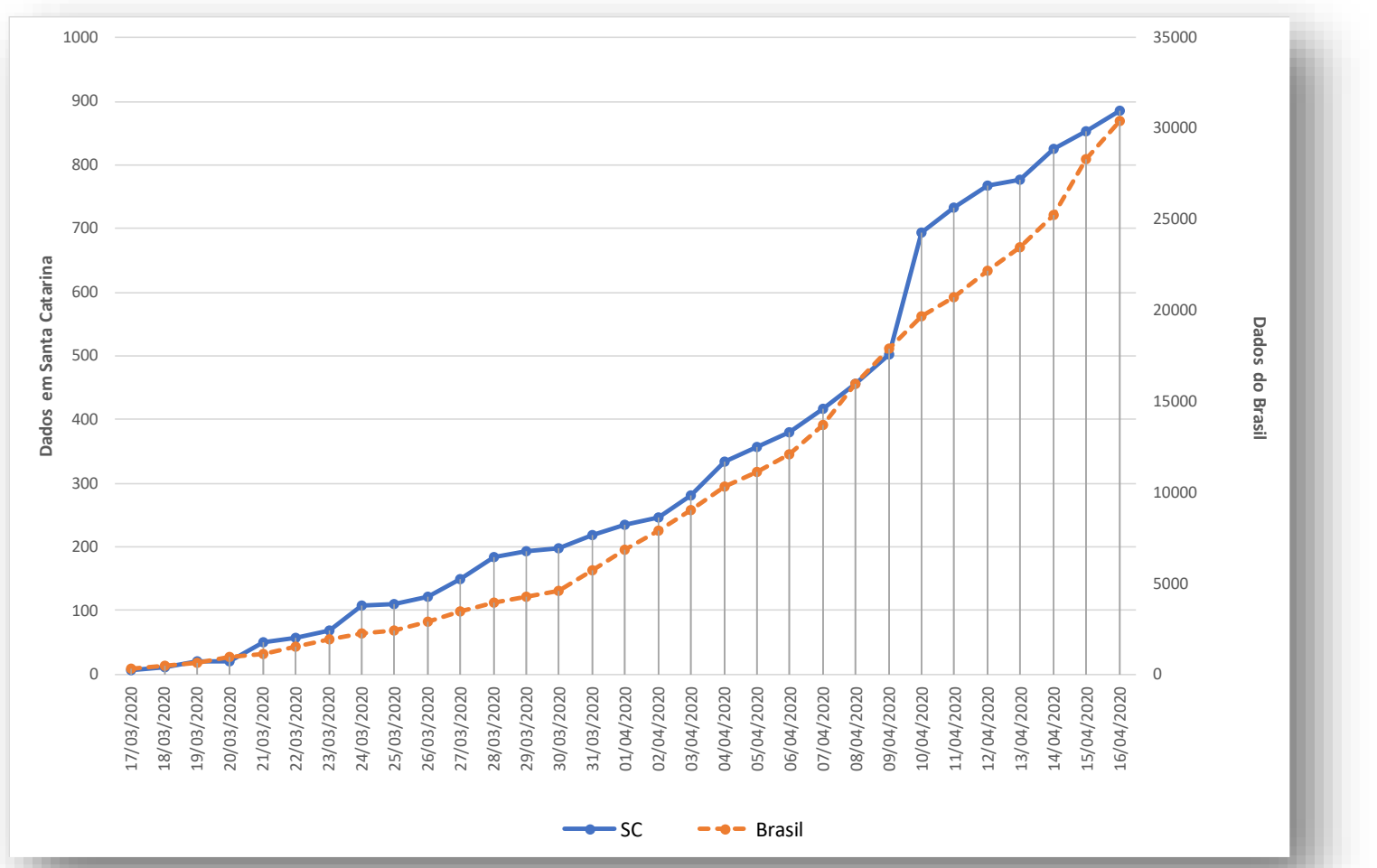

Fonte: Criado pelos pesquisadores (2020), a partir dos dados do Painel de casos de doença pelo Coronavírus 2019 (COVID-19) no Brasil pelo Ministério da Saúde, disponível em https://covid.saude.gov.br

Created by researchers (2020), based on data from the 2019 Coronavirus Disease Panel (COVID-19) in Brazil by the Ministry of Health, available at https://covid.saude.gov.br

Algumas datas para situar nosso território. O Brasil teve o primeiro caso confirmado em 26 de fevereiro de 2020, logo após o feriado de Carnaval. No dia 11 de março, a OMS, diante dos acontecimentos pelo mundo, decretou estado de pandemia, que é uma epidemia que acontece em todo o mundo. O Estado de Santa Catarina, foi uma das primeiras unidades federativas a assumir as orientações da OMS. O Brasil, de maneira estranha, apresentou um debate diferente entre o Ministério da Saúde, que seguiu os indicativos da OMS e o presidente, que em muitos momentos, pautou-se no senso comum. Durante o período de geração dos dados, o Ministério da Saúde foi coordenado pela equipe do ex-Ministro Luiz Henrique Mandetta (Democratas/MS). Como este texto está construído durante os acontecimentos da pandemia e o processo de reterritorialização não cessa, apresentaremos no Gráfico 1 intitulado número de contaminados pelo Coronavírus, dados de casos confirmados, comparando Brasil com Santa Catarina, para entender os números que configuraram o contexto da pesquisa.

Com este contexto, pensando o sistema educacional em solo catarinense, encontramos os decretos do governo do Estado de Santa Catarina. O Decreto n. 509, de 17 de março de 2020, determina a suspensão das aulas em todas as unidades de ensino e em todos os níveis por um período de trinta dias. Segundo o texto, os quinze primeiros dias da rede pública estadual correspondem à antecipação do recesso escolar. Publicado no mesmo dia, o Decreto n. 515 declara a situação de emergência para fins de prevenção e combate à epidemia do COVID-19 e também aponta no texto a suspensão das atividades escolares, junto com outras, pelo período de trinta dias. Passada uma semana, no dia 23 de março, o Decreto $n$. 525, estende o período de 
ausência das aulas presencias até 31 de maio. No mesmo ato fica decretado que os estudantes não sejam prejudicados no cumprimento do calendário letivo e que as aulas deverão ser repostas oportunamente. Os três decretos mencionados, quanto ao sistema escolar, trazem a suspensão das atividades presenciais corroborando com a prática de isolamento social.

O título do artigo sugere a existência de um professor em crise. $\mathrm{O}$ texto tem por intenção fugir do uso que o senso comum faz da palavra crise. A partir disso, cabe uma questão, que tipo de discurso existe quando se fala de "crise sanitária" ou "crise econômica"? Neste texto trataremos de crise a partir de um viés filosófico. Abbagnano (2007) ao discutir o tema, recupera a noção hipocrática de crise, com origem etimo-

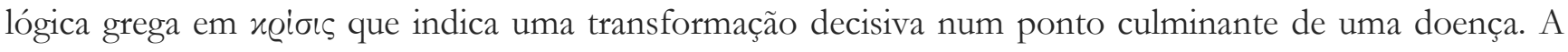
partir do ponto, se estabelece uma nova orientação diretiva. Esta percepção se aproxima com a ideia de crise como o momento de escape de um território produzido por ondas de desestabilização. Ideia apresentada por Deleuze e Guattari (2011). A desestabilização não é o ponto final, mas a passagem do território para uma reterritorialização. Aproximando os autores, o processo de crise, poderia ser uma nova orientação diretiva, recuperando Abbagnano (2007), sem a pretensão de rigidez, como demonstra Deleuze e Guattari (2011). Então, temos a ideia de crise que norteará a reflexão feita posteriormente, dos dados obtidos do relato da professora que se autodenomina uma professora em crise. A crise ao qual a professora se refere é a crise no viés filosófico. Em seu relato, é possível perceber suas considerações a cada momento vivido, a cada obstáculo comunicacional evidenciado, e cada estratégia de superação adotada para manter a qualidade e a acessibilidade do ensino durante o período de isolamento social no Estado de Santa Catarina.

Dito isto, segue o texto que será dividido em três partes. Na primeira parte, faremos a exposição metodológica onde aportar-se-á as escolhas e recortes cartografados, passando pelos conceitos de cartografia social e phármakon ( $\varphi \propto \varrho \mu \alpha x o ́ v)$. Na seção seguinte, o diário de bordo das experiências e vivências de uma professora durante o período de isolamento social. E por fim, a última parte apresentaremos as considerações, cartografando as escolhas teóricas e o relato da professora que aqui expomos.

\section{METODOLOGIA E OUTROS CAMINHOS TEÓRICOS}

Para pensar este trabalho, enquanto construção e enquanto objeto de análise, escolhemos o método da cartografia inspirados numa escrita deleuzo-guattariana. Para além deste conceito, nesta seção abordaremos a ideia de phármakon numa tentativa de aproximação dialógica com o COVID-19 e por fim, conceituar o que entendemos, neste texto, educação à distância $(\mathrm{EaD})$ e aula prática.

A cartografia é um modo de se fazer pesquisa que, segundo Passos et al. (2007), não se prende a regras prontas com objetivos enrijecidos. É evidente que se caminha com metas, por se tratar de uma pesquisa, mas não são constituídos de maneira tradicional, com metas pré-fixadas, rumo a um norte fixo, mas, caminha-se. As metas estão ali, mas podem apresentar rupturas assignificantes e propor novas conexões ou linhas de fuga. A cartografia é uma construção dada por um processo de individuação, por que "toda pesquisa é uma intervenção" (PASSOS et al., 2009, p. 17) que pressupõe uma transversalidade. Cabe ao pesquisador, neste território transversal três ações de pesquisa que são, descrever, intervir e criar definições. Os autores, partem de uma leitura deleuzo-guattariana para pensar um método que desestabilize a unidade com vistas ao acompanhamento de processo com fim de pensar uma "habitação de um território, que ele [o pesquisador] não habita" (PASSOS et al., 2009, p. 56).

O trabalho do pesquisador, numa cartografia, é explorar um território existencial. Isso significa que a aproximação do pesquisador, com o espaço que ele pretende vivenciar, dar-se-á pelo engajamento, pois 
“sujeito e objeto se codeterminam” (PASSOS et al., 2009, p. 131). A ligação entre o pesquisador e pesquisa se define pela sensibilidade dada através do plano dos afetos. A cartografia é uma afetividade da ordem do desejo. Segundo Passos et al. (2007), ela se faz numa prática de relato que pode ser escrita ou desenhada em um diário de campo, ou em um caderno de anotações. Tal instrumento reúne uma memória material construída processualmente. O ente envolvido com o pesquisador não é mero objeto da pesquisa, mas faz parte intrínseca na construção de novas conexões possíveis.

A cartografia, segundo Deleuze e Guattari (2011), visa acompanhar processos em vez de representar objetos. Propõe um conhecimento como invenção de si e invenção do mundo por meio de uma cartografia da vida prática, não se reduzindo em representar uma realidade pré-existente e enrijecida. A cartografia é aproximativa do rizoma. Em certo grau, o resultado da cartografia provê a detecção de signos e forças. Com a intencionalidade de perceber a força de um evento que rompe um ciclo habitual, vislumbrando o redirecionamento da cotidianidade, adotaremos a cartografia como caminho para pensar o ensinar do professor em tempos de crise sanitária, e a importância da comunicação nesse processo. Dada estas características, pensar um diário temporal é assertivo fazê-lo sobre a ótica de cartografia inventiva de si e do mundo.

A segunda ideia que apresentaremos nesta seção é a de phármakon. Por ora, ela aparecerá desterritorializada, e nas considerações finais apresentaremos alguns entrelaçamentos. O filósofo francês Jacques Derrida (2005) afirmou que "a pharmacéia, levou à morte uma pureza virginal e um íntimo impenetrado". O vocábulo grego phármakon pode ser usado tanto como remédio, como também, veneno. Ambos, ao entrarem em contato com um corpo qualquer, produzem transformações. A ação pharmacéia consiste na atuação interna, incorpórea, para demonstrar externamente novos sintomas ou a cura. Por exemplo, uma dor de cabeça. Externamente poucos são os sintomas visíveis, mas internamente, o sujeito pode ser acometido por um grande desconforto. Quando ingerido o phármakon, há transformações substanciais que podem levar o "doente" a uma melhora ou uma piora. Convém mencionar que o uso do phármakon não é exclusivo do doente.

O efeito causado, quando da melhora, pode em certo grau, tornar o uso do phármakon corriqueiro ou repetitivo, conduzindo o "doente" a uma dependência. Quando do efeito contrário, caso o sujeito continue vivo, há procura por uma substância de outra natureza, mas ainda um phármakon. A questão que incomoda Derrida (2005), nesta reflexão, é a quem pertence o poder de determinar o valor da phármakon? Há uma noção de poder e de domínio sobre outrem. Não há um uso inocente da coisa em si. Há uma destruição da pureza causada por uma ideia de morte, ou por evita-la. Não é nossa intenção, neste artigo, apresentar um debate ético acerca do tema, mas considerar a existência de uma certa intencionalidade sobre a phármakon ou pelo menos, a intencionalidade política que atravessa o discurso em torno deste problema.

Via de regra, escolhas políticas sobre o phármakon obedecem a uma estrutura de poder e uma hierarquia de natureza normativa. Isso nos faz questionar, quais são os mecanismos farmacológicos que podem, ou não, ser aplicados no caso da pandemia do COVID-19 e quais são os discursos que o motivam. Como diz Derrida, "não há remédio inofensivo" (2005, p. 46). Em outras palavras, o valor da ação do remédio, ou do veneno, consiste numa submissão civilizatória, como aponta Melchioretto (2014), pois o uso do phármakon é uma decisão política ligada a princípios. "Seja pelo ideário de beleza, seja pela manutenção da saúde, seja pelo restabelecimento do que já se encontra enfermo ou ainda na busca do paradigma de felicidade" (MELCHIORETTO, 2014, p. 49). O phármakon está ligado a um ideário de consumo e hedonismo. A questão é: quais são os interesses políticos que são intrínsecos às escolhas relativas a um phármakon pensando o COVID-19? Não é nossa intenção responder essa questão, apenas problematiza-la para pensarmos as entrelinhas possíveis numa cartografia. Com esta discussão pretendemos levantar uma possibilidade de, mais 
adiante, discutir alguns phármakon diante do isolamento.

Para dar conta de algumas outras questões presentes no relato, há outros elementos que merecem nossa atenção e conceituação. Um deles é o Ensino a Distância (EaD). A prática no Brasil não é nova, mas o início do nosso século é marcado pelas investidas na $\mathrm{EaD}$, com foco no ensino superior, com a criação da Universidade Aberta do Brasil (UAB), com objetivo de democratizar e ampliar o acesso ao ensino superior, como sugere Alonso (2014).

A principal diferença entre a educação presencial e a educação a distância é que no último caso não há necessidade da presença física do estudante, que executa as atividades, estudo, avaliações, a distância. A presença do estudante se dá de forma virtual. Essa situação leva a necessidade do uso de tecnologias de informação e comunicação (TICs), por parte das instituições que ofertam os cursos EaD. O documento intitulado Documento de Recomendações - Ações Estratégicas em Educação Superior a Distância em Âmbito Nacional, elaborado pela Secretaria de Educação Superior (SESu), datado de 2005, considera, sobre o uso das TICs na educação à distância,

que as necessidades de estruturação de sistemas tecnológicos estivessem submetidas a objetivos pedagógicos, que os elementos para consecução dos sistemas não fossem considerados como exigências de um cheklist, mas necessários à modelagem de um curso, daí: material de apoio online dispostos em Biblioteca Digital, caracterização de trajetórias de aprendizagem com o uso de recursos para armazenamento e análise de logs, sistemas de gerenciamento de Banco de Dados, Sistemas Tutores Inteligentes e recursos de controle e retroalimentação de aprendizagem. Para além disso, o documento propunha ação efetiva dos alunos na criação, intercâmbio e socialização de suas experiências em relação ao uso dos recursos tecnológicos, bem como a experimentação como elemento catalisador nas ações da EaD (ALONSO, 2014, p.43).

Isso indica a necessidade de projetar um curso para a aplicação EaD. Em virtude da pandemia global gerada pelo COVID-19, no Brasil, no entanto, o que se viu foi uma adaptação de unidades curriculares práticas e teóricas, que então eram ministradas presencialmente, para o uso das TICs. O que gerou um formato de ensino que não é EaD, nem ensino presencial. Chamamos de ensino remoto. E, como Santa Catarina foi o primeiro Estado da federação a iniciar o isolamento social, e em concordância com a Organização Mundial da Saúde e o então ministro da Saúde no Brasil, mas contrariando o presidente Jair Messias Bolsonaro (sem partido), a ação do governo do Estado pró-isolamento social foi um tanto abrupta e de, certo modo, de surpresa. Em um dia estávamos em sala e, no outro, proibidos de ministrar aulas presenciais.

\section{DIÁRIO DE UM PROFESSOR EM CRISE}

O diário de bordo, foi construído durante no período de 16 de março a 24 de abril de 2020, dentro do período de isolamento proposto por uma instituição de ensino federal de Santa Catarina, momento em que se tentava evitar a propagação do Coronavírus.

O isolamento, proposto pela Portaria do(a) Reitor(a) $N^{\circ}$ 1211, de 18 de março de 2020, em vista do Decreto $N^{\circ}$ 515, de 17 de março 2020, do Governo do Estado de Santa Catarina, que declarou estado de emergência no Estado de Santa Catarina, deu início no dia 17 de Março de 2020 com previsão de fim no dia 16 de Abril de 2020. A portaria de isolamento social, como medida preventiva, previa suspensão das aulas de regime presencial, suspensão do atendimento ao público, suspendendo também todo o serviço presencial. Desta forma, docentes e administrativo iniciariam suas atividades de trabalho remoto.

A portaria, no entanto, saiu um dia após a Portaria do(a) Reitor(a) Nº 1178, de 16 de março de 2020, 
que suspendia as aulas por 15 dias, e ainda informava a manutenção do calendário acadêmico. Os estudantes, em sistema de isolamento, receberiam os materiais e orientação do professor utilizando os ambientes virtuais da instituição, a saber, SIGAA e Moodle. A medida tomou a todos de assalto, docentes de atividades práticas se viram isolados, munidos apenas de seu conhecimento, e equipamentos eletrônicos com internet.

Era o terceiro dia de isolamento quando efetivamente foi possível começar a receber o retorno dos estudantes sobre o uso das mídias digitais institucionais. Alguns viram-se isolados, munidos muitas vezes apenas de um celular com acesso limitado a internet.

Dificuldades de acesso, eram-nos relatadas pelos líderes das turmas, utilizando o mensageiro instantâneo WhatsApp. Assim, muitos solicitavam os materiais à professora que vos relata, via Whats $A p p$, para encaminhar aos colegas de turma, o mesmo era feito com áudios, conversações que auxiliavam a tirar dúvidas e imagens.

Para orientações quanto às atividades de Ensino, Pesquisa e Extensão da Portaria do(a) Reitor(a) $N^{\circ}$ 1211, de 18 de março de 2020, em seu item II solicitava que,

Independentemente do canal usado para a articulação, orientação das atividades, a entrega deve ser feita exclusivamente pelos canais oficiais do IFSC a fim de garantir os registros, quais sejam: SIG, E-MAIL e MOODLE (INSTITUIÇÃO FEDERAL DE SANTA CATARINA, 2020, p.4).

E, ao ler a portaria, enquanto pensava em formas de adaptar o material prático de aula para pessoas com deficiência de acesso, pautada em toda minha experiência docente e estudos pedagógicos pensei, "que os jogos comecem" (expressão famosa de um longa-metragem de terror). Sim, de fato, foi um momento de terror.

É importante salientar que as turmas que eu lecionava a unidade curricular de Modelagem manual para o vestuário eram duas, do curso Técnico de Vestuário, e uma do ensino superior em Design de Moda, compostos de 90 estudantes de idades que variavam entre 18 e 51 anos, de variadas classes sociais. Não houve tempo de preparo para entrega de material físico, de repente, tínhamos o que havia em casa, para manter o calendário acadêmico, utilizando ferramentas EaD em cursos presenciais para unidades curriculares práticas.

Cientes que não seriam aulas $\mathrm{EaD}$, iniciamos adaptações razoáveis. Os três primeiros dias foi uma resposta aos recursos utilizados. Os chats abertos nos sistemas institucionais não tiveram participantes. Coordenadores e professores incessantemente avisavam os estudantes que não eram férias. Necessitavam manter o calendário acadêmico. Ao fim do terceiro dia, já passadas das $22 \mathrm{~h}$, depois de muitos recados pelo líder utilizando Whats App, consegui alguns e-mails pessoais dos estudantes, para orientações que foram feitas individualmente. A busca por e-mails pessoais deu-se para garantir que os estudantes iriam receber as mensagens, uma vez que, o meio virtual é dinâmico e também, pode-se dizer, solúvel, muitos e-mails cadastrados na plataforma institucional não eram mais acessados pelos mesmos, e os e-mails institucionais ainda não haviam sido criados para os estudantes dos primeiros semestres. Mas, ao fim do quarto dia, depois de muito tentar levá-los aos meios institucionais, me rendi, e permiti que me inserissem no grupo de Whats App. Afinal,

nosso papel não é falar ao povo sobre a nossa visão do mundo, ou tentar impô-la a ele, mas dialogar com ele sobre a sua e a nossa. Temos de estar convencidos de que a sua visão do mundo, que se manifesta nas várias formas de sua ação, reflete a sua situação no mundo, em que se constitui (FREIRE, 2014, p.49).

Freire (2014) fez entender que, durante o isolamento social, período que distanciava as comunicações verbais comuns, nos privava do sentido do tato, da fala pela gesticulação, do sentir o olhar e o tom da voz, 
e da compreensão dos sentidos propostos em uma comunicação natural que flui entre docente e discentes, durante uma aula, seria, no entender a visão de mundo do estudante, e as particularidades ao qual se inseria nesse momento, que seria possível desenvolver o ato de educar e aprender.

Compreendia, ao fim do terceiro dia de isolamento, que nada me adiantariam sistemas repletos de atividades, como chat, fórum, e-mail, notícias, bate-papo, diante da falta de autonomia estudantil, e falta de acesso. Cito a falta de autonomia, pois, em modo EaD, executando suas atividades, também, de forma remota, utilizando seus acessos limitados de internet, demoraram 3 dias para nos reportar suas dificuldades, abaixo de muita insistência no contato com líderes via Whats App. A busca pelo conhecimento do lado de lá ocorria lentamente, enquanto a tentativa de contato do lado de cá era frenética. Dessa forma, recorrendo a Paulo Freire (2014), mais uma vez compreendi que enquanto professor, deveria adequar o trabalho docente a forma de comunicação que os discentes já haviam incorporado em seu mundo.

No quarto dia de isolamento meditei. O dia seria longo, o stress era de toda uma equipe de docentes, que, em grupos de Whats App, Hangout (mensageiro instantâneo do Google) e e-mail, discutiam formas de aproximação, recados, dificuldades e estratégias de aula. Era ainda o quarto dia de isolamento, acessei o sistema institucional para abrir um chat, essa ação envia uma mensagem ao e-mail dos estudantes. "Chat em manutenção" era a mensagem na sala de bate papo. Então abri um fórum, que havia sido a solução prevista durante capacitação docente, feita pela instituição, para que nos informássemos melhor das funções dos sistemas institucionais. O fórum, soube por outra professora, não estava funcionando. Imediatamente enviei outra mensagem avisando, pedindo desculpas, e abri um bate papo em outra plataforma, esta então, funcionária.

Uma guerra. Com tantos instrumentos, os estudantes não conseguiam acesso, os sites institucionais não funcionavam em versão mobile para execução de atividades. Apenas visualização. Vimo-nos na trincheira, atirando com baionetas de brinquedo. Era o fim do quarto dia de isolamento, eu tinha um chat vazio, e seis estudantes, apenas, em acompanhamento via e-mail.

As adaptações, até o momento, haviam sido: ficar online no e-mail, durante o horário de trabalho, e online via chat, durante o horário de aula. Transmitir material de apoio aos estudantes via sites institucionais, e efetuar questionários online utilizando Google Forms, por facilidade de acesso, disponibilizando link nos sites institucionais. Ao fim do quarto dia de isolamento, apenas o Google Forms funcionou, enviado via $W h a t s A p p$ pelo líder da turma.

O formulário, um questionário criado na plataforma Google, permite um link de acesso rápido. Foi composto de 20 questões com respostas curtas, muitas das quais múltipla escolha. O quê, em parte, explica o resultado positivo. Da amostragem de 90 estudantes, foi enviado para 45, e respondido por 34. Os demais 45 estudantes que não responderam à pesquisa eram do curso superior em Design de Moda, e não se enquadravam na ementa dos demais para respondê-lo.

As atividades eram as mesmas que as feitas em sala de aula, basicamente, modelar. No entanto, houve adaptações também. Estudantes do terceiro semestre do curso técnico estavam fazendo seus projetos integradores, havíamos recém começado a executar os moldes para looks escolhidos individualmente, pelos estudantes. Estudantes do primeiro semestre do curso técnico executavam modelagens de base, intercalando conteúdos teóricos a medida do necessário. Estudantes do terceiro semestre do curso superior faziam estudos de partes estruturais e, necessitavam criar. Já os estudantes do primeiro semestre do curso superior intervalavam-se entre um trabalho em grupo e a leitura de artigos para responder aos questionários propostos.

Por meio de softwares e mídias sociais foi possível manter a interação com maior parte dos estudan- 
tes. As dificuldades em migrar de um modelo presencial para um modelo EaD, com atividades adaptadas, materiais e equipamentos igualmente adaptados estavam presentes nas informações trazidas pelos estudantes. Estávamos diante de uma ação avisada de um dia para no outro, iniciarmos a proposta de adaptação EaD. De todos os nossos implicantes, tais quais, a falta de internet, os meios com os quais encontrar e contactar os estudantes, as atividades possíveis e os materiais que poderiam ser adaptados, havia ainda o tempo, este último implicava na organização e autonomia dos estudantes para as atividades propostas. Nesse ponto, considerar as dificuldades de uma forma generalizada guiou a produção de vídeos, tutoriais e a escolha pelo chat e fórum, e mesmo pelo Whats $A p p$, já que havia uma dificuldade no uso das plataformas institucionais.

A falta de materiais de uso prático, equipamentos específicos, tais quais réguas específicas e carretilha, papel kraft dentre outros, mostraram-se um desafio, bem como a falta de conhecimento acerca do acesso dos estudantes às TICs. A primeira semana de aulas em formato remoto ocorreu mais de forma a auxiliar estudantes para o uso das tecnologias disponíveis, do que para de fato produzir conhecimento de modelagem. Mas, em uma semana, a instituição já havia feito a listagem de estudantes sem acesso às TICs, e disponibilizava a todos os materiais necessários, bem como atividades impressas aos estudantes sem acesso a TICs.

A instituição, igualmente, preocupava-se com a capacitação de docentes para o uso das TICs e formatos pedagógicos de atividade remota. Mantendo, com estas ações, a intenção de permitir o acesso e manutenção das aulas.

Foi, de fato, somente a partir do meio da segunda semana de aulas adaptadas para o EaD, que os estudantes se tornaram mais participativos, engajados e, apenas após muitas solicitações, e-mails para os estudantes cadastrados no sistema oficial da instituição, que foi possível iniciar a análise de eficiência das atividades e dos métodos escolhidos para interação.

A seguir, serão detalhados os softwares e atividades propostas, com resultados de sua aplicação, efetuando uma análise sobre a efetividade destas atividades em vista das propostas objetivadas na aplicação de cada uma.

Num primeiro momento, foi necessário adaptação dos conteúdos curriculares, que pudessem ser acessados tanto pelos sistemas institucionais quanto nos celulares, então foram analisadas opções de fazer atividades com uso de softwares livres. Percebeu-se a inexistência de bons softwares próprios para a prática de modelagem manual a distância.

As opções eram duas, gravar um vídeo efetuando a modelagem necessária, com as explicações, sem ter um aparato próprio, e também sem ter materiais específicos para esta prática a distância, uma vez que, pra uma boa apresentação em vídeo, seria necessária suporte para celular, mesa própria para a prática da modelagem, e papéis e canetas que pudessem dar contraste no traçado enquanto os diagramas fossem sendo construídos. Além, é claro, de um ângulo certo para garantir a boa visualização dos discentes.

A outra opção, que foi a escolhida, foi montar tutoriais em vídeo em programas que criassem o traço passo a passo, e permitissem inserir legendas. O software Video Scribe supriu esta demanda. Este software permitiu finalizar os tutoriais em vídeo. Como os vídeos ficaram muito grandes para inserção nas plataformas institucionais, e mesmo para visualização em celular, requeriam alto consumo de dados, foram compactados utilizando um aplicativo online gratuito, o Clipchamp.

Concomitante ao envio dos tutoriais, foi necessário acompanhamento individual, que se mostrou muito mais efetivo, obtendo a participação dos estudantes, via e-mail, e pelo Whats App. Materiais de apoio foram sendo incluídos nas plataformas institucionais, e paralelamente enviadas pelo Whats App. Passando-se 
as quatro semanas iniciais de isolamento social, já haviam sido distribuídos materiais para que os estudantes pudessem efetuar suas atividades em casa, e a instituição havia feito treinamentos para uso das plataformas institucionais.

Em 23 de março de 2020 por meio do Decreto n. 525, o governo do Estado de Santa Catarina decreta extensão do período de isolamento social por 30 dias:

Contados a partir de 19 de março de 2020, as aulas nas unidades da rede pública e privada de ensino, municipal, estadual e federal, incluindo educação infantil, ensino fundamental, nível médio, educação de jovens e adultos (EJA), ensino técnico e ensino superior, sem prejuízo do cumprimento do calendário letivo, o qual deverá ser objeto de reposição oportunamente (SANTA CATARINA (Estado), 23 Março 2020, p. 2)

Decidindo por manter o calendário letivo, o Conselho Superior (CONSUP) da instituição federal, localizada no Vale do Itajaí, decidiu continuar com as atividades remotas, e aulas adaptadas para EaD. Foram feitas pesquisas da diretoria com coordenadores e docentes, e a decisão favorável a continuidade das atividades manteve o trabalho remoto e estendeu o período de isolamento no campus. A instituição ampliou o isolamento social por mais 30 dias, voltaríamos no final de abril. Mas, em 11 de abril de 2020 o governador Carlos Moisés da Silva, (PSL/SC), em entrevista indicou novo prazo para abertura das escolas, até dia 31 de maio (DN, 2020).

O preparo dos materiais para melhor compreensão dos estudantes, no entanto, continuava gerando desafios. A aula prática exige conteúdos além dos que podemos encontrar em leituras que são os aprimoramentos profissionais que repassamos aos discentes, tais como: formas de segurar o esquadro, melhor maneira de medir partes curvas, o jeito correto de cortar o molde, e estas informações não poderiam ser negligenciadas.

Estas informações poderiam ser repassadas por videoaula, no entanto, esta representava um desafio de visibilidade do processo de modelagem. A estratégia utilizada foi o acompanhamento individual, por vídeo chamada no WhatsApp, e no software Google Meet (comunicador por vídeo chamada), que foi disponibilizado gratuitamente pela Google, bem como foi disponibilizada pela instituição em uma parceria com a empresa, que migrou também e-mails e deu acesso a outras ferramentas da Google.

A busca por novos softwares que possibilitassem criar um material de apoio que os discentes pudessem baixar, guardar e utilizar sempre que tivessem dúvidas. Foram criados tutoriais fixos, não mais em vídeo, utilizando o software Corel Draw na versão teste por 15 dias. Essa opção permitia repassar todas as informações necessárias, de forma escrita, mais criar os passos que pudessem ser guardados e acompanhados sempre que necessário. Foi notado que muitos estudantes continuavam suas rotinas de trabalho, não estavam cumprindo o estudo no horário da aula, que era das $18 \mathrm{~h} 30$ às $22 \mathrm{~h} 30$.

Era 15 de abril, a coordenação do núcleo de vestuário havia feito o levantamento dos estudantes com dificuldades de acesso à internet, e então, disponibilizou material impresso, que foi levado aos discentes. Os materiais foram colocados à disposição na instituição, para retirada em horário específico. E reuniões pelo Hangout e pelo Google Meet haviam sido feitas para discutir estratégias de organização dos trabalhos interdisciplinares. Uma nova rotina que significou mais horas de trabalho, e uma mudança completa no método de preparo das aulas.

Era a quarta semana de abril quando, como professora, experimentei uma situação corriqueira para os discentes, mas não para quem preparava as aulas. Faltou-me internet. Precisava agora preparar o material, e permitir acesso de alguma forma aos discentes, bem como manter o acompanhamento das atividades 
práticas e teóricas com o que era disponível em um smartphone com plano pré-pago de 4G.

Neste dado momento, a instituição havia conseguido migrar todas as contas de todos os estudantes e servidores, da plataforma institucional para a plataforma Google Sala de Aula, possibilitando, ao menos para o uso de e-mail, acesso mais rápido e leve, possível do celular. O acompanhamento das atividades foi dado por e-mail. Cada atividade recebida contabilizava frequência do estudante no período de isolamento social. O preparo das atividades continuou sendo por meio de tutoriais, que foram criados no computador, transferidos ao celular, e então enviados aos estudantes em seus grupos de WhatsApp pelo celular. O WhatsApp mostrou ser uma plataforma rápida e de pouco uso de dados da internet, permitindo não só o envio de materiais, mas o acompanhamento das atividades e tempo real.

No entanto, o Whats App não era uma ferramenta institucional e, apesar de ter sido liberada para uso, não permitia o registro e documentação do que foi exercido durante o período. Para manter registro institucional, a plataforma foi acessada via celular para cadastrar uma notícia para as turmas, avisando sobre a nova situação da professora, essa ação foi demorada e ocupou muitos dados da internet, mas foi possível. Essa notícia era repassada pela plataforma aos e-mails dos estudantes, garantindo recebimento. Também, para manter o registro, foi mantido o uso de e-mail, facilitado pela plataforma do Google Sala de Aula.

Foram mantidos também, caso o estudante assim preferisse, o uso de Hangout e chamadas de vídeo pelo Whats App, permitindo reuniões de acompanhamento de atividades teóricas na primeira, e acompanhamento de atividades práticas na segunda. Essas ferramentas mostraram-se indispensáveis para manter o bom andamento dos conteúdos durante o período de isolamento.

Outra estratégia utilizada foi o envio de links com vídeos do YouTube, mostrando como executar transformações de bases em moldes de peças. Utilizou-se essa estratégia para repassar conteúdo novo aos estudantes da terceira fase, de forma que eles poderiam acompanhar o conteúdo enquanto executavam a atividade. O tema escolhido foi alfaiataria industrial, que representava certo grau de dificuldade. Essa atividade foi bem recebida, apesar de o acesso a vídeos ser difícil para alguns estudantes.

Esse relato findou-se antes do término do período de isolamento social, em 24 de abril de 2020. Mas foi, pela experiência de cartografar as atividades executadas, as dificuldades existentes e as estratégias utilizadas que a crise pelo qual passou a professora que aqui vos relata, partiu do senso comum de problema, para um conceito mais próximo da transformação que não teria sido possível sem material e apoio suficientes para que os problemas se transformassem em obstáculos transponíveis.

\section{ENTRELAÇAMENTOS}

Na primeira frase da introdução, falávamos da noite do réveillon e como algumas datas, ou celebrações marcam nossas vidas. O tempo é de certa forma sempre marcado. Ele é possuidor de uma marca, de um signo. O tempo gere nossa vida e as diferentes atividades no qual o sistema de vida nos condiciona. A crise sanitária decorrida do Coronavírus modificou, não só os votos do réveillon como também a marcação de tempo nos mais diferentes setores de nossa sociedade. Neste contexto, a escola precisou, sem "tempo" adequar-se ao "novo tempo". Uma mudança drástica de metodologia, práticas, costumes e espaços diante do novo cenário. O relato do profissional de educação deixou evidente as angústias de uma corrida em busca de um novo tempo. Mas as angústias do docente também foi a angústia do discente que num primeiro “tempo" não sabia como adequar seu tempo às necessidades das instituições de ensino.

No sentido dos entrelaçamentos encontrados durante a leitura do relato, foi elaborado na Figura 1 a cartografia do diário de uma professora em crise. Nesta imagem, busca-se expor a relação vivenciada no 
momento de crise iniciado pelo isolamento social para conter a propagação da doença causada pelo vírus COVID-19 em Santa Catarina. Nesse momento de crise, e isolamento social, perpassaram pela vivência pessoal, enquanto professora, as múltiplas realidades discentes, as dificuldades técnicas pela necessidade do uso de TICs, e mesmo, a necessidade do uso de TICs para comunicação entre docente e discentes. Perpassou ainda, e talvez mais intensamente, o tempo vivido e o tempo desejado. Todos estes elementos fazem parte do phármakon escolhido pela professora, a partir do uso de ferramentas diversas e de mídias sociais para adequar-se ao contexto do momento.

Figura 1: Cartografia do diário de uma professora em crise / Cartography of the diary of a teacher in crisis

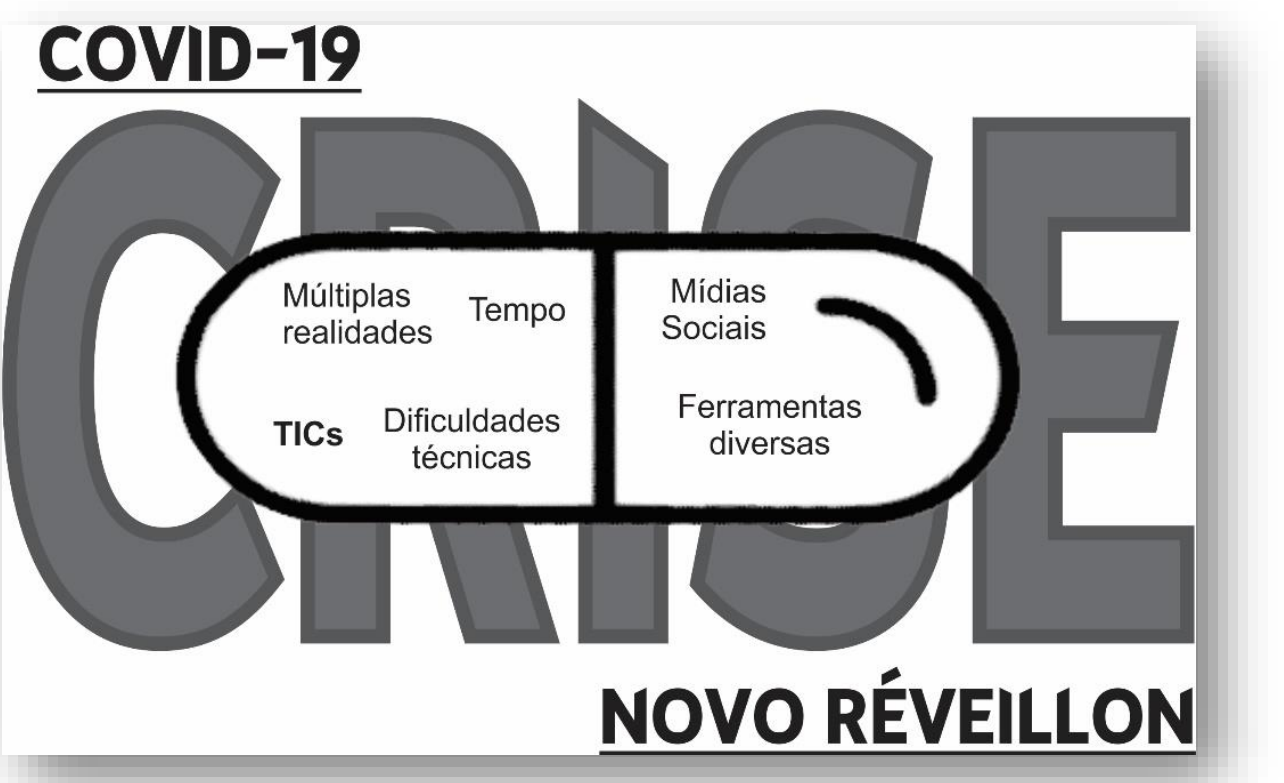

Fonte: Elaborado pelos pesquisadores a partir dos dados da pesquisa (2020) / prepared by the researchers from the research data (2020).

O tempo é marcado de diferentes percepções. Como também o acesso aos meios de comunicação entre discentes e docentes. Há uma crença que todos nós estejamos conectados. Porém, é preciso cuidado ao defender tal percepção. A confecção ao ciberespaço com boas condições ainda é um privilégio de alguns lugares e de pessoas dispostas a pagar por este tipo de serviço. O diário revelou estudantes com dificuldades de acesso, problemas técnicos e inexistência de acesso em alguns pontos. O isolamento social vivenciado em tempos de COVID-19, foi para alguns também tempos de isolamento virtual. O tempo passou de maneira diferente, e muitos impedidos de acesso aos ambientes virtuais e ferramentas propostas não puderam dar conta de acompanhar as exigências escolares. A questão que cabe, talvez, será que encontraremos algum mecanismo que seja capaz de mensurar a aprendizagem virtualizada em tempos de conexões precárias? Talvez, acima desse posicionamento, nos caiba indagar por que as plataformas educacionais ainda representam uma dificuldade comunicacional entre docente e discente, não só do acesso, mas da compreensão do sistema e interação responsiva com ele.

Tenho tempo e estou virtualmente ligado, já posso fazer minha atividade? Caberia muito bem esta questão. Porém, o que o diário revelou foi uma dificuldade técnica de acesso e manuseio de ferramentas oficiais. A instituição de ensino aqui abordada usou de várias estratégias. Neste momento, se o docente entra 
em crise por conta das várias possibilidades, como pensar a outra ponta. O que acessar? Onde ir? Como me conectar? O que usar? Ufa! São tantas as questões, e aí, já posso fazer minha atividade? Apesar de nosso tom "sarcástico" pensar uma estrutura de ensino e aprendizagem mediada por tecnologias virtualizadas requer um tempo de preparação, e aqui, o tempo não foi disponibilizado. Talvez, e só talvez, esta ausência temporal seja um elemento fundante na geração de uma crise ao docente envolvido e empoderado na condução de estratégias de ensinar e aprender.

A docente, que teve seu tempo de planejamento de aula perpassado por reuniões de planejamento docente e treinamento para uso das plataformas institucionais de ensino, bem como posteriormente, treinamento para uso de aplicativos de ensino disponibilizados pela plataforma da Google Sala de Aula, vivenciou, em um primeiro momento, o choque que gera a crise. Para só num segundo momento, observar o discente, e a necessidade de fluir um processo comunicativo entre docente e discente para permitir a viabilidade do ensinar e aprender. Dessa crise, surge a escolha pelo phármakon que se mostrou mais eficiente, neste caso as TICs que já permeavam a vida do discente em seu cotidiano, dosando a medida desse phármakon com a necessidade de controle docente e registro institucional.

O diário de borda deixou evidente, pelo relato da angústia que o uso de tecnologias virtualizadas requer um determinado tipo de conhecimento técnico. O uso de um aplicativo de mensagens instantâneas, o Whats App, e como ele foi essencial no processo de comunicação, deixou evidente que o domínio sobre uma ferramenta, não transforma um usuário habilitado para uso de outras ferramentas mais específicas. Vide a "crise" da própria instituição migrando das ferramentas previamente anunciadas, como o Moodle, para o Google Sala de Aula e o uso de uma outra, o já mencionado Whats App com grupos não institucionalizados para fazer-se comunicar. Em meio a esta enxurrada informacional estava o docente, tentando mediar, decretos governamentais, portarias institucionais, necessidade docente e a possibilidade discente: um espaço de múltiplas ferramentas, nem sempre demostra como sendo um espaço de aproximação.

O tempo do COVID-19 é tempo diferente. Falamos no presente porque a construção deste texto acontece durante a crise sanitária. É um tempo diferente porque vive-se um período de exigentes diferentes daquelas no qual o sistema já nos habitou a viver. Múltiplas realidades, modos e condições de acesso à rede mundial com contextos singulares, desconhecimento de ferramentas educacionais, dependências de ferramentas de mídia social marcam um universo, que poderíamos classificar de "estranho". Aqui há um ponto para retomarmos uma ideia já abordada neste texto, que é o conceito de phármakon.

A pharmacéia se constitui a partir de uma ideia de morte, qual é a ideia de morte que aqui está envolvida? Não falamos da tragicidade do COVID-19, mas falamos da morte de um sistema escolar que se construiu um torno de uma rigidez arborescente, para usar uma expressão deleuzo-guattariana. A escola, vista como caule, obrigou-se a desenhar um novo mapa, uma nova estratégia e sem tempo. Daí a necessidade de estabelecer algum tipo de phármakon. Ainda não é possível mensurar se as práticas distanciadas da escola física foram as mais adequadas. O relato do diário prevê um estado de angústia que gera, consequentemente, uma crise. Talvez, e só talvez, o indicativo pharmakológico pudesse ser a reterritorialização da educação. Mas tudo ainda é dito e pensado no campo especulativo.

Percebe-se, pelo relato, que nesse tempo, aos processos educacionais e comunicacionais, fazem-se presentes a necessidade de controle e registro. Não necessariamente para o processo de ensinar e aprender, mas para a condição do atual modelo educacional, que necessita das notas e presenças como meio de avaliar a participação e conhecimento discente. Essa participação é compreendida como a frequência e o conhecimento apresentado por ele denota o nível de aprendizado adquirido. O conhecimento gerado, no entanto, só pode ser medido a partir do processo de comunicação entre discentes e docente. 
O uso do phármakon neste tempo não é inocente. Há um teor político que revela um discurso de poder. As escolhas são pautadas por interesses. Não desejamos estabelecer uma discussão ética sobre elas. Mas houve o rompimento de ciclo habitual sugerindo uma reterritorialização forçada. $\mathrm{O}$ acompanhamento deste processo requer um olhar de atenção para si e para o mundo. A saída encontrada através da virtualização das atividades pode ser lida como um phármakon de momento, bem como a escolha da docente por tecnologias de informação e comunicação mais íntimas. O estabelecimento de novos signos e novas forças. Mas não foi uma estratégia de aproximação afetiva, ainda. A vida prática, marcada por um novo tempo, é o retrato de uma necessidade. Resta-nos saber, para qual direção este phármakon levará, se é para o restabelecimento do sistema anterior ao CONVID-19, para a manutenção daquilo que tempos ou o surgimento de uma Nova Terra, conforme Deleuze e Guattari (2011) prescrevem.

Os signos e forças que temos descritos a partir do diário não retrata uma reterritorialização possível, mas retrata que uma reterritorialização é possível. Tudo a depender da phármakon escolhida, ou imposta na espera de um novo réveillon.

\section{Referências}

ABBAGNANO, Nicola. Dicionário de filosofia. 5 Ed. São Paulo: Martins Fontes, 2007.

ALONSO, Katia Morosov. A EaD no Brasil: sobre (des)caminhos em sua instauração. Educar em Revista, Curitiba, Brasil, Edição Especial n. 4/2014, p. 37-52. Editora UFPR.

DELEUZE, Gilles; GUATTARI, Félix. Mil Platôs: capitalismo e esquizofrenia 2. 2. ed. São Paulo: Editora 34, 2011.

DERRIDA, Jacques. A farmácia de Platão. São Paulo: Iluminuras, 2005.

DN. Diário do Nordeste. Governador de Santa Catarina libera comércio de rua, mas amplia fechamento de escolas e shoppings. Folhapress, 11 de abril de 2020. Disponível em https://diariodonordeste.verdesmares.com.br/editorias/pais/online/governador-de-santa-catarina-libera-comercio-de-rua-mas-amplia-fechamento-de-escolas-e-shoppings-1.2233313. Acesso em: 15.abr.2020.

FREIRE, Paulo. Pedagogia do oprimido. 56 Ed. rev. e atual. Rio de Janeiro: Paz e Terra, 2014.

INSTITUIÇÃO FEDERAL SANTA CATARINA. Portaria Do(a) Reitor(a) $n^{\circ} 1178$, de 16 de março de 2020. Florianópolis, Disponível em: https://www.ifsc.edu.br/documents/30681/1852909/Portaria+retificada/6ace3bca-9a62-4ff7-a0c2-92352072ada4. Acesso em: 15 abr. 2020.

INSTITUIÇÃO FEDERAL SANTA CATARINA. Portaria Do(a) Reitor(a) $n^{\circ} 1211$, de 18 de março de 2020. Florianópolis, Disponível em: https://www.ifsc.edu.br/documents/30681/1852909/Portaria+1211_Altera+Portaria+1178_Suspensao+das+Atividades+IFSC_Coronavírus.pdf/2ebcbf4a5b1a-4336-bca4-6c95c8a5490d. Acesso em: 15 abr. 2020.

PASSOS, Eduardo; KASTRUP, Virgínia; ESCÓSSIA, Liliana da. Pistas do método da cartografia: pesquisa-intervenção e produção de subjetividade. Porto Alegre: Sulina, 2009.

MELCHIORETTO, Albio Fabian. Sobre as drogas e algumas implicações filosóficas. Revista Filosofia, ciência e vida, Ano VII, n. 91, p. 45-50. Editora Escala: São Paulo, 2014.

MATTEI, Lauro. A importância de se manter o isolamento e o distanciamento social como instrumentos para controlar a expansão do novo Coronavírus em Santa Catarina. Texto para discussão 36/2020. Centro Socioeconômico: Universidade de Santa Catarina (UFSC), Florianópolis, 2020. Disponível em: <https://noticias. paginas.ufsc.br/files/2020/04/texto-na-íntegra.pdf>. Acesso em: 
19 abr. 2020.

SANTA CATARINA (Estado). Decreto n 509, de 17 de março de 2020. Dá Continuidade à Adoção Progressiva de Medidas de Prevenção e Combate Ao Contágio Pelo Coronavírus (covid-19) nos órgãos e nas Entidades da Administração Pública Estadual Direta e Indireta e Estabelece Outras Providências. Florianópolis, SC, 17 mar. 2020. p. 1-3. Disponível em: http://www.saude.sc.gov. br/coronavirus/arquivos/decreto509-17-03-2020.pdf. Acesso em: 20 abr. 2020.

Decreto $n^{\circ} 515$, de 17 de março de 2020. Declara situação de emergência em todo o território catarinense, nos termos do COBRADE $n^{\circ}$ 1.5.1.1.0 - doenças infecciosas virais, para fins de prevenção e enfrentamento à COVID-19, e estabelece outras providências. Florianópolis, SC, 17 mar. 2020. p. 1-3. Disponível em: http://www.saude.sc.gov.br/coronavirus/arquivos/decreto_515_17_03_20.pdf. Acesso em: 20 abr. 2020.

. Decreto $n^{\circ}$ 525, de 23 de março de 2020. Dispõe sobre novas medidas para enfrentamento da emergência de saúde pública de importância internacional decorrente do Coronavírus e estabelece outras providências. Florianópolis, SC, 23 mar. 2020. Disponível em: http://www.sau de.sc.gov.br/coronavirus/arquivos/DEC_525_COMPILADO.pdf. Acesso em: 15 abr. 2020.

Artigo recebido em: 28 de abril de 2020

Artigo aceito em: 02 de junho de 2020 